\section{Images in Cardiovascular Disease}

Check for updates

\title{
A Rare Case of Cardiac Involvement in Rosai-Dorfman Disease
}

\section{OPEN ACCESS}

Received: May 25, 2019

Revised: Jul 2, 2019

Accepted: Jul 2, 2019

Address for Correspondence: Stavros Mantzoukis, MD, MSC

Department of Cardiology, General Hospital of Ioannina 'G. Hatzikosta', 1 Makrigianni Str, Ioannina 45500, Greece.

E-mail: stavrosmantzoukis@gmail.com

Copyright (c) 2019 Korean Society of Echocardiography

This is an Open Access article distributed under the terms of the Creative Commons Attribution Non-Commercial License (https:// creativecommons.org/licenses/by-nc/4.0/) which permits unrestricted non-commercial use, distribution, and reproduction in any medium, provided the original work is properly cited.

ORCID iDs

Nikolaos Tsigaridas (ID)

https://orcid.org/0000-0002-2853-1618

Stavros Mantzoukis (iD)

https://orcid.org/0000-0002-1975-9151

Konstantinos Mpakas (D)

https://orcid.org/0000-0002-1561-6313

Efstratios Troganis (iD)

https://orcid.org/0000-0002-4496-777X Dimitrios Patsouras (D)

https://orcid.org/0000-0001-9892-8541

Conflict of Interest

The authors have no financial conflicts of interest.

\author{
Nikolaos Tsigaridas $\mathbb{1}$, MD, MSc', Stavros Mantzoukis $\mathbb{D}$, MD, MSc', \\ Konstantinos Mpakas $\left(\mathbb{D}, \mathrm{MD}^{1}\right.$, Efstratios Troganis $\left(\mathbb{D}, \mathrm{MD}^{2}\right.$, and \\ Dimitrios Patsouras $\mathbb{D}, \mathrm{MD}^{1}$
}

'Department of Cardiology, General Hospital of Ioannina 'G. Hatzikosta', Ioannina, Greece ${ }^{2}$ Department of Cardiology, Sismanoglio-Amalia Fleming General Hospital of Athens, Athens, Greece

A 70-year-old female patient was transferred to our institution from a community hospital for coronary angiography after a non ST-elevation myocardial infarction. Her medical history was significant for the presence of Rosai Dorfman disease (RDD) for which was treated with low dose methylprednisolone. She had known abdominal lymphadenopathy and had also undergone right nephrectomy 5 years earlier due to right kidney involvement. At that time there was no cardiac involvement. Coronary angiography disclosed an intermediate severity stenosis of the right coronary artery and conservative management was decided. Transthoracic echocardiography revealed a sizeable mass of $4.5 \times 4 \mathrm{~cm}$ in the right atrium showing enhancement after injection of echocardiographic contrast agent (Figure 1). Transesophageal echocardiography disclosed the presence of a right atrial mass encircling the cavity. It involved the right atrial free wall and the interatrial septum. It surrounded the ostium of the superior vena cava and the coronary sinus without causing obstruction (Figure 2). The mass was considered as the recurrence of past same disease and no other confirmative diagnostic process was made, regarding that there was no extra-nodal involvement. Due to the absence of hemodynamic abnormalities, we decided against interventional treatment and the patient was advised on periodic clinical and echocardiographic screening. NSTEMI could not be associated with RDD because the mass is not located near its right coronary artery orifice.

$\mathrm{RDD}$ is a very rare, non-malignant disease caused by proliferation of non-Langerhans sinus histiocytes. ${ }^{1}$ It is characterized of massive, painless and mainly bilateral cervical
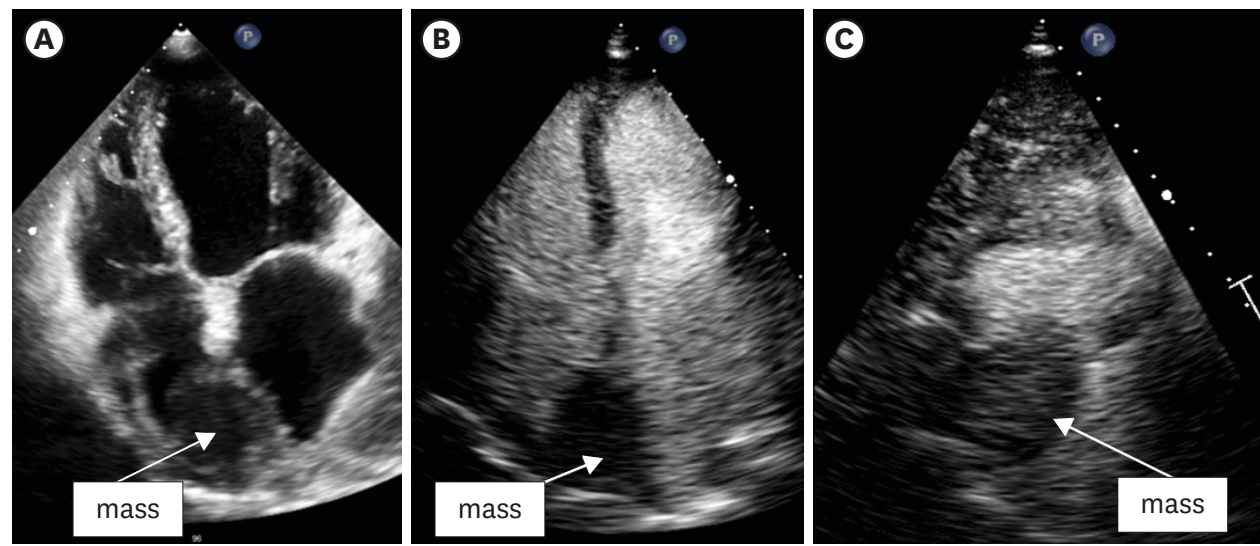

Figure 1. Transthoracic echocardiogram: four chamber view showing a mass in the right atrium and the interatrial septum before (A) and after contrast (B) injection. (C) A subcostal view showing contrast enhancement of the mass. 

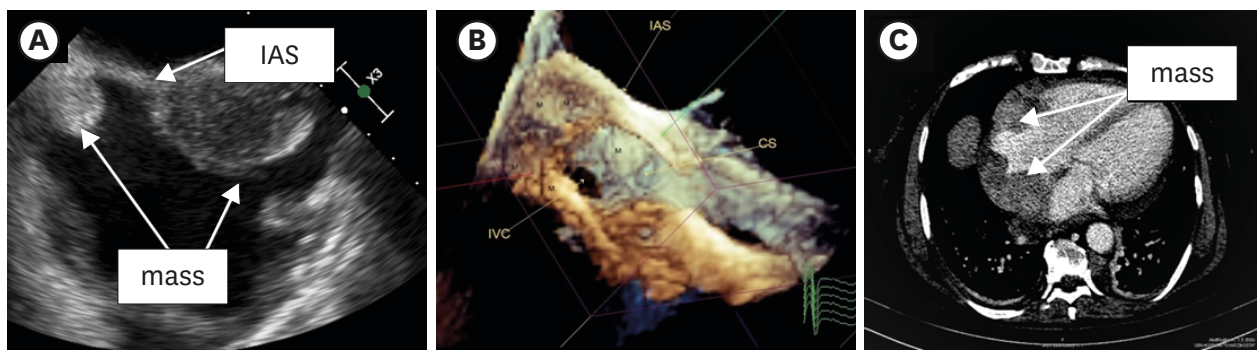

Figure 2. (A) Transesophageal echocardiographic $2 \mathrm{D}$ bicaval view showing the relation of the mass to the interatrial septum and the orifices of the superior and the inferior vena cava and (B) 3D view of the right atrium showing the relation of the mass to the interatrial septum and the orifices of IVC and CS. (C) Chest CT with contrast administration performed 6 months before presentation showing the mass virtually encircling the right atrial cavity. CS: coronary sinus, IAS: interatrial septum, IVC: inferior vena cava.

lymphadenopathy in childhood or early adulthood. ${ }^{2)}$ Cardiac involvement is rare in RDD with only 17 cases previously reported in the English literature. Of these, the right atrium was affected in 7 while in some cases there was involvement in more than one cardiac locations. ${ }^{3)}$ Treatment options include corticosteroids chemotherapy, radiotherapy and surgery local phenomena. ${ }^{2)}$

\section{REFERENCES}

1. Rosai J, Dorfman RF. Sinus histiocytosis with massive lymphadenopathy. A newly recognized benign clinicopathological entity. Arch Pathol 1969;87:63-70. PUBMED

2. Dalia S, Sagatys E, Sokol L, Kubal T. Rosai-Dorfman disease: tumor biology, clinical features, pathology, and treatment. Cancer Control 2014;21:322-7. PUBMED | CROSSREF

3. Heidarian A, Anwar A, Haseeb MA, Gupta R. Extranodal Rosai-Dorfman disease arising in the heart: clinical course and review of literature. Cardiovasc Pathol 2017;31:1-4.

PUBMED | CROSSREF 